\title{
Large Calcified Thyroid Cyst with Escherichia Coli Abscess
}

Dr. Medic Ovidiu-Angel Matei", Carolin Niethammer, Wolfram Lamade, Martin Sonnentag

Department of Visceral Surgery, Helios Hospital Pforzheim, Germany

DOI: $10.36347 /$ sasjs.2021.v07i02.009

| Received: 17.01.2021 | Accepted: 30.01.2021 | Published: 10.02.2021

*Corresponding author: Dr. Medic Ovidiu-Angel Matei

\section{Abstract}

This case highlights the rare occurrence of a large benign calcified cyst with Escherichia coli abscess of the right lobe of the thyroid gland associated with colloid nodular goiter, hyperglycemic derailment, tracheal compression and deviation.

Keywords: large thyroid cyst, Escherichia coli abscess.

Copyright $\left({ }_{0} 2021\right.$ The Author(s): This is an open-access article distributed under the terms of the Creative Commons Attribution 4.0 International License (CC BY-NC 4.0) which permits unrestricted use, distribution, and reproduction in any medium for non-commercial use provided the original author and source are credited.

\section{INTRODUCTION}

Cystic thyroid degeneration with subsequent calcification and abscesses are uncommon and may be seen in long standing nodular goiters. However, large calcified thyroid cyst causing symptoms of thyroid abscess with tracheal compression and deviation, associating hyperglycemic derailment are not commonly reported in literature [1]. When they occur, however, they may lead to significant morbidity including a thyroid storm stairway obstruction, sepsis [2-5]. Hyperglycemic derailment is known to be associated with adverse outcome and increased mortality [6-8].

\section{Case Presentation}

A 78-year-old female who was presented to our emergency department experienced hyperglycemic derailment (blood sugar level was $893 \mathrm{mg} / \mathrm{dl}$ ) with and a red anterior neck swelling. She had no known medicalillnesses, history of neck trauma, pre-existent thyroid. Apart from a low grade pyrexia at $37,6{ }^{\circ} \mathrm{C}$, her vital signs were: heart rate 112 beats per minute, pulse per minute, blood pressure $130 / 80 \mathrm{~mm} \mathrm{Hg}$ and respiratory rate normal.
The blood investigations including full blood count, urea and electrolytes and coagulation were screened (Table):

\begin{tabular}{|llc|}
\hline \hline CRP & $21.48 \mathrm{mg} / \mathrm{dl}$ & $(0-5 \mathrm{mg} / \mathrm{dl})$ \\
\hline WBCC & $17.2 / \mathrm{nl}$ & $(4.3-10.8 / \mathrm{nl})$ \\
\hline free T3 & $2.24 \mathrm{pmol} / \mathrm{l}$ & $(3.1-6.8 \mathrm{pmol} / \mathrm{l})$ \\
\hline free T4 & $18.71 \mathrm{pmol} / \mathrm{l}$ & $(12-22 \mathrm{pmol} / \mathrm{l})$ \\
\hline TSH & $0.09 \mathrm{mIE} / \mathrm{l}$ & $(0.27-4.2 \mathrm{mIE} / \mathrm{l})$ \\
\hline Glucose & $837 \mathrm{mg} / \mathrm{dl}$ & $(82-115 \mathrm{mg} / \mathrm{dl})$ \\
\hline HbA1c-IFCC $129.0 \mathrm{mmol} / \mathrm{molHb}$ \\
\begin{tabular}{l} 
(21.3-44.3 mmol/molHb) \\
\hline HbA1c-NGSP $14.0 \% \mathrm{Ges} . \mathrm{Hb}$
\end{tabular} & $(4.8-6.0 \% \mathrm{Ges} . \mathrm{Hb})$ \\
\hline
\end{tabular}

She was admitted to Intermediate Care Unit and stabilized. After stabilisation of the emergency patient, we find out a history of enlargement of goiter for 20 years with a low painful, red anterior neck-side swelling for one month. She had progressively worsening difficulty in breathing with intermittent dysphagia for solids. Examination revealed a hard and low painful, red, warm mass arising from the right thyroid lobe measuring $11 \mathrm{~cm} \times 10 \mathrm{~cm}$ in size with symptoms of local infiltration and gross tracheal deviation to the left side (Fig 1). There was no cervical lymphadenopathy. 


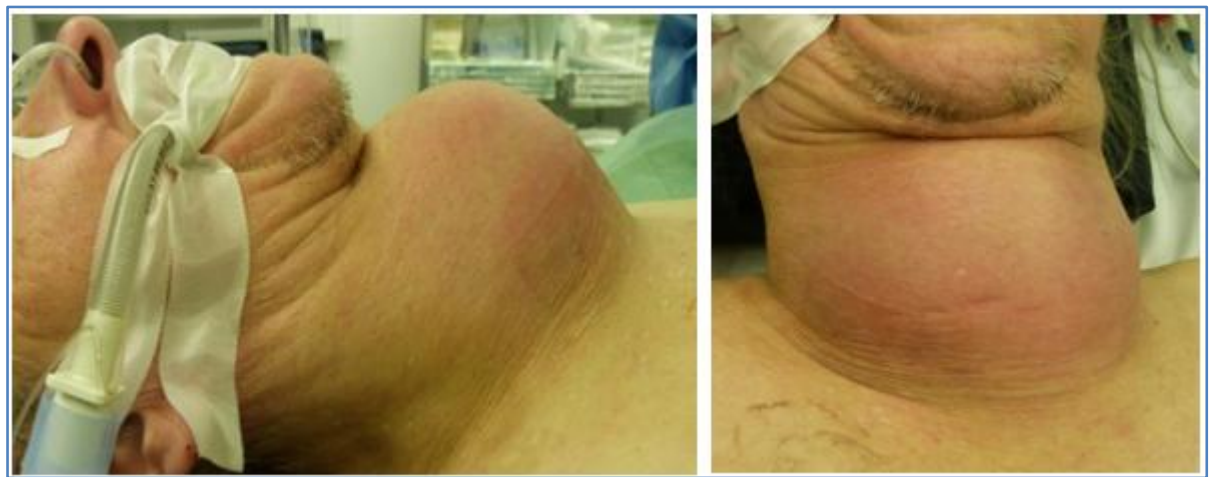

Fig-1: Anterior and lateral view showing a large, hard and tender mass of the neck with signs of a abscess (view before operation)

Ultrasound scan showed a large calcified thyroid cyst and right thyroid nodules. The patient had ultrasound guided aspiration under aseptic technique with aspiration of abscess pus.

She had an urgent CT scan which showed a large calcified thyroid cyst with thick enhancing wall and abscess measuring $10 \times 9 \times 9,2 \mathrm{~cm}$ (Fig 2. A and B), compressing and displaying the trachea to the left side (Fig 3) and almost occupying the whole right thyroid lobe and a hypodense lesions over the right hemithyroid measuring 3,2 x 4,2 x 2,4 cm. The left thyroid lobe and isthmus appeared normal.

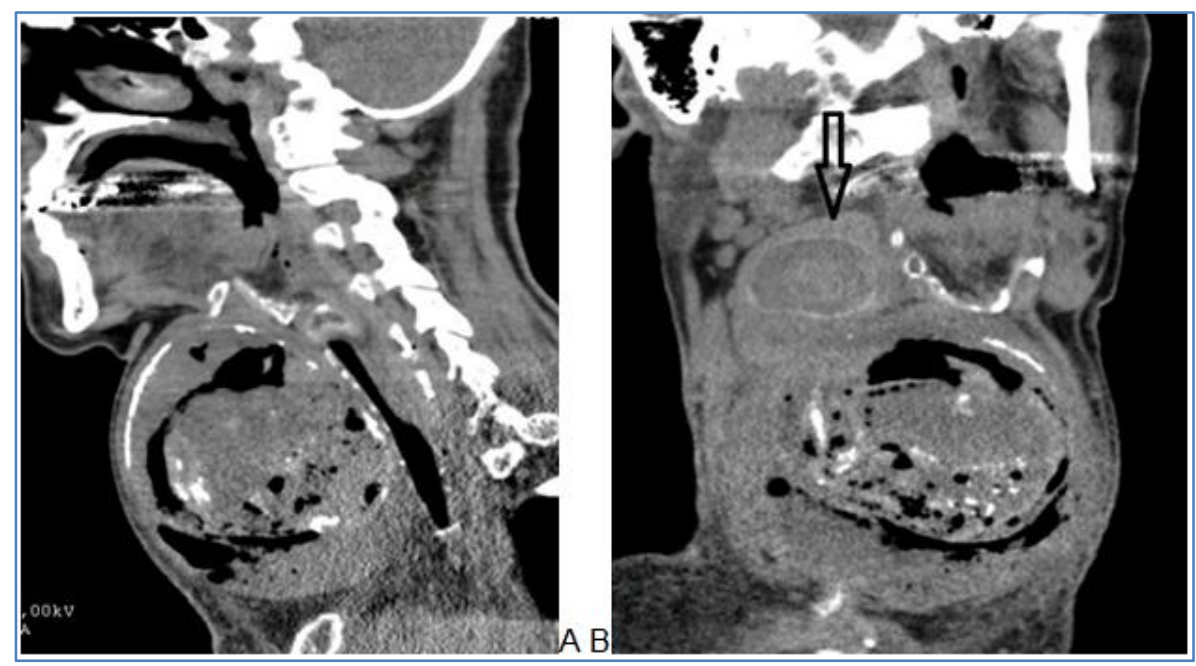

Fig-2: CT-Scan of head and neck showing the large calcified thyroid abscess (measuring $10 \times 9 \times 9,2 \mathrm{~cm}$ ) with significant tracheal stenosis (view $A$ ) and and a hypodense lesions over the right hemithyroid measuring 3,2 x 4,2 x $2,4 \mathrm{~cm}$ (arrow view B)
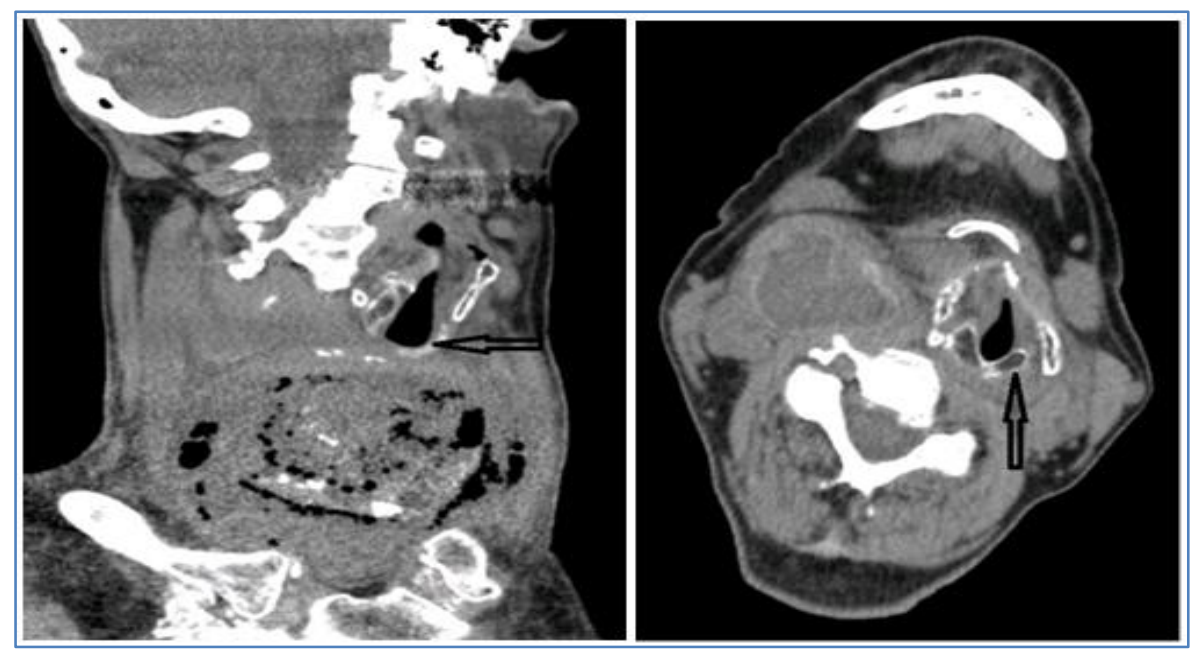

Fig-3: CT-Scan of head and neck showing a significant tracheal deviation to the opposite side (Arrow) 
The patient underwent intravenous antibiotic and was taken for surgery after stabilisation. The neck was explored with Kocher suprasternal inscion. There was extensive subcutaneous edema. The deep investing cervical fascia, strap muscles and thyroid capsule were matted together with complete obliteration of dissection planes. There was extensive phlegmone and edema. The calcified cyst with abscess was completely removed (Fig 4) from the thyroid gland and remaining right lobe were not dissected. The wound was not closed. She was admitted to Intensive Care Unit after surgery. A day after she underwent an second-look operation with a right hemithyroidectomy.

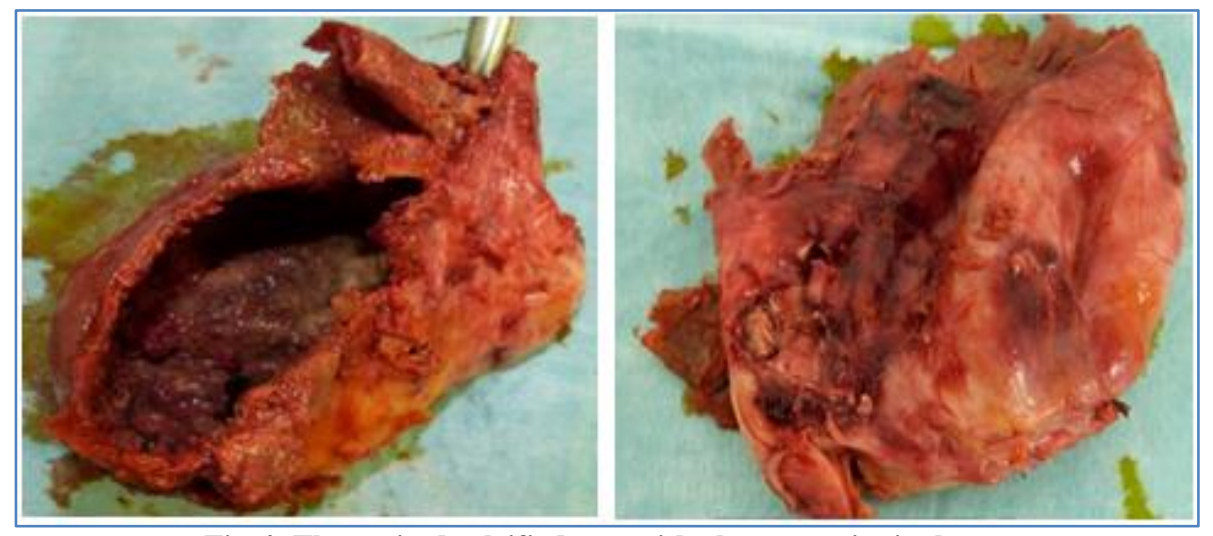

Fig-4: The excised calcified cyst with abscess cavity is shown

Histology of the thyroid abscess revealed the presence of an cervical soft tissue with severe scarring, chronic granulating, large scaled abscessing, necrotizing inflamation of the adjacent thyroid parenchyma. No evidence of malignancy. Histology of the right hemithyroid revealed the presence of an colloid nodular goiter with high-grade regressive changes, fresh hemorrhages and a $1,5 \mathrm{~cm}$ follicular adenoma, no abscess, no malignancy. Escherichia coli was isolated from the aspirate.

The patient recovered with hypothyroidism, without voice alterations or recur-rence. She was diagnosticated of type 2 diabetes (first diagnosis) and the treatment was adjusted. Antibiotics were continued seven days post-operative.

She was discharged after 10 days on Metformin $500 \mathrm{mg} / \mathrm{Januvia} 50 \mathrm{mg} /$ Lantus 16IE/ LThyroxin $75 \mathrm{mg}$ daily.

\section{DISCUSSION}

Several recent studies have shown an association of insulin resistance with thyroid nodular disease. Accumulating evidence suggest that the recent increase in the incidence of thyroid nodular disease, in iodine replete areas, is related to the increased prevalence of insulin resistance [9]. Hyperglycemia is a common condition in critically ill patients. Patients admitted to an intensive care unit represent an inhomogeneous collective and hyperglycemia might need a differential evaluation depending on the underlying disorder. Hyperglycemic derailment is known to be associated with adverse outcome and increased mortality [10-12].

\section{CONCLUSION}

Calcification of a large thyroid cyst with Escherichia coli abscess is a rare phenomenon. Unusually, in the patient reported here, the thyroid abscess was confluent with colloid nodular goiter and hyperglycemic derailment. The majority of such obstructive calcified thyroid cyst are benign. Imaging with ultrasound and CT scan may have to be utilised to determine the extent of the lesion before surgery.

\section{Author contributions}

All authors contributed equally to the manuscript drafting. All authors read and approved the final manuscript. All authors have no conflict of interest to declare.

\section{Informed consent}

Informed consent was obtained from patient.

\section{REFERENCES}

1. Lyons R, Waters PS, Sugrue C, Kerin MJ. An unusual presentation of a calcified thyroid gland Case Reports. 2012 Dec 10;2012:bcr2012007844.

2. Fonseca IF, Avvad CK, Sanchez EG, Henriques JL, Leão LM. Acute suppu-rative thyroiditis with multiple complications. Arq Bras Endocrinol Metab.2012;56(6):388-92.

3. Deshmukh HG, Verma A, Siegel LB. Stridor: the presenting feature of athyroid abscess. Postgrad Med J. 1994;70:847-50.

4. Jonas NE, Fagan JJ. Internal jugular vein thrombosis: a case study and review ofthe literature. Internet J Otorhinolaryngol. 2007;6:2.

5. Suprabha J, Vijay K, Shital P. Acute bacterial thyroid abscess as a complicationof septicemia. IDCP. 2000;9:383-6.9. 
6. Capes SE, Hunt D, Malmberg K, Gerstein HC. Stress hyperglycaemia and increased risk of death after myocardial infarction in patients with and without diabetes: a systematic overview. The Lancet. 2000 Mar 4;355(9206):773-8.

7. Van den Berghe, G. Molecular biology: A timely tool for further unraveling the "diabetes of stress". Crit. Care Med. 2001, 29, 910-911.

8. Laird AM, Miller PR, Kilgo PD, Meredith JW, Chang MC. Relationship of early hyperglycemia to mortality in trauma patients. Journal of Trauma and Acute Care Surgery. 2004 May 1;56(5):1058-62.

9. Ayturk S, Gursoy A, Kut A, Anil C, Nar A, Tutuncu NB. Metabolic syndrome and its components are associated with increased thyroid volume and nodule prevalence in a mild-tomoderate iodine-deficient area. European Journal of Endocrinology. 2009 Oct 1;161(4):599.

10. Capes SE, Hunt D, Malmberg K, Gerstein HC. Stress hyperglycaemia and increased risk of death after myocardial infarction in patients with and without diabetes: a systematic overview. The Lancet. 2000 Mar 4;355(9206):773-8.

11. Van den Berghe G. Molecular biology: a timely tool for further unraveling the "diabetes of stress". Critical care medicine. 2001 Apr 1;29(4):910-1.

12. Laird AM, Miller PR, Kilgo PD, Meredith JW, Chang MC. Relationship of early hyperglycemia to mortality in trauma patients. Journal of Trauma and Acute Care Surgery. 2004 May 1;56(5):1058-62. 